\title{
Intelligent Watermarking Techniques
}




\section{Series on Innovative Intelligence}

Editor: L. C. Jain (University of South Australia)

\section{Published:}

Vol. 1 Virtual Environments for Teaching and Learning (eds. L. C. Jain, R. J. Howlett, N. S. Ichalkaranje \& G. Tonfoni)

Vol. 2 Advances in Intelligent Systems for Defence (eds. L. C. Jain, N. S. Ichalkaranje \& G. Tonfoni)

Vol. 3 Internet-Based Intelligent Information Processing Systems (eds. R. J. Howlett, N. S. Ichalkaranje, L. C. Jain \& G. Tonfoni)

Vol. 4 Neural Networks for Intelligent Signal Processing (A. Zaknich)

Vol. 5 Complex Valued Neural Networks: Theories and Applications (ed. A. Hirose)

Vol. 6 Intelligent and Other Computational Techniques in Insurance (eds. A. F. Shapiro \& L. C. Jain)

Forthcoming Titles:

Biology and Logic-Based Applied Machine Intelligence: Theory and Applications (A. Konar \& L. C. Jain)

Levels of Evolutionary Adaptation for Fuzzy Agents

(G. Resconi \& L. C. Jain) 


\section{Intelligent Watermarking Techniques}

Editors

Jeng-Shyang Pan

National Kaohsiung University of Applied Sciences, Taiwan

\section{Hsiang-Cheh Huang}

National Chiao Tung University, Taiwan

\section{Lakhmi C. Jain}

University of South Australia 
Published by

World Scientific Publishing Co. Pte. Ltd.

5 Toh Tuck Link, Singapore 596224

USA office: Suite 202, 1060 Main Street, River Edge, NJ 07661

UK office: 57 Shelton Street, Covent Garden, London WC2H 9HE

\section{British Library Cataloguing-in-Publication Data}

A catalogue record for this book is available from the British Library.

\section{INTELLIGENT WATERMARKING TECHNIQUES (WITH CD-ROM)}

Copyright $(\mathcal{O} 2004$ by World Scientific Publishing Co. Pte. Ltd.

All rights reserved. This book, or parts thereof, may not be reproduced in any form or by any means, electronic or mechanical, including photocopying, recording or any information storage and retrieval system now known or to be invented, without written permission from the Publisher.

For photocopying of material in this volume, please pay a copying fee through the Copyright Clearance Center, Inc., 222 Rosewood Drive, Danvers, MA 01923, USA. In this case permission to photocopy is not required from the publisher.

ISBN $981-238-955-5$ 


\section{PREFACE}

Watermarking techniques involve the concealment of information within a text or images and transmit this information to the receiver with minimum distortion. This is a very new area of research. These techniques will have a significant effect on defence, business, copyright protection and other fields where information needs to be preserved at all cost from attackers.

This book presents the recent advances in the theory and implementation of watermarking techniques. It brings together for the first time the successful applications of intelligent paradigms, including comparisons with conventional methods, in many areas as listed in the table of contents.

We believe that this book will be of great value to undergraduate and postgraduate students of all disciplines including engineering and computer science. It is targeted at researchers, scientists, and practising engineers who wish to improve their productivity by developing successful information systems.

We are grateful to the authors for their valuable contributions. We express our appreciation to the reviewers for their time and expert advice. Our thanks are due to the editorial staff of the World Scientific Publishing Company for their assistance in the preparation of the manuscript.

Peter Jeng-Shyang Pan

Hsiang-Cheh Huang

Lakhmi Jain 
This page intentionally left blank 


\section{CONTENTS}

Preface

Part I. Fundamentals of Watermarking and Intelligent Techniques

Chapter 1. An Introduction to Watermarking Techniques

Hsiang-Cheh Huang, Hsueh-Ming Hang, and Jeng-Shyang Pan

Chapter 2. Neuro-Fuzzy Learning Theory

Yan Shi, Masaharu Mizumoto, and

Peng Shi

Chapter 3. Evolutionary Algorithms

Wei-Po Lee and Chao-Hsing Hsu

Chapter 4. A Tutorial on Meta-Heuristics for

Optimization

Shu-Chuan Chu, Chin-Shiuh Shieh, and John F. Roddick

\section{Part II. Watermarking Techniques}

Chapter 5. Watermarking Based on Spatial Domain

Hsiang-Cheh Huang, Jeng-Shyang Pan, and Hsueh-Ming Hang

Chapter 6. Watermarking Based on Transform Domain Hsiang-Cheh Huang, Jeng-Shyang Pan, and Hsueh-Ming Hang 
Chapter 7. Watermarking Based on Vector Quantization 165 Chin-Shiuh Shieh, Hsiang-Cheh Huang, Zhe-Ming Lu, and Jeng-Shyang Pan

Chapter 8. Audio Watermarking Techniques

Hyoung Joong Kim, Yong Hee Choi, Jongwon Seok, and Jinwoo Hong

Chapter 9. Video Watermarking: Requirements,

Problems and Solutions

Christoph Busch and Xiamu Niu

Chapter 10. Digital Video Watermarking: Techniques, Technology and Trends

Deepa Kundur, Karen Su, and

Dimitrios Hatzinakos

Chapter 11. Benchmarking of Watermarking Algorithms Nikolaos Nikolaidis and Ioannis Pitas

\section{Part III. Advanced Watermarking Techniques}

Chapter 12. Genetic Watermarking on Transform Domain Hsiang-Cheh Huang, Jeng-Shyang Pan, and Feng-Hsing Wang

Chapter 13. Genetic Watermarking on Spatial Domain Feng-Hsing Wang, Lakhmi C. Jain, and Jeng-Shyang Pan

Chapter 14. Robust Image Watermarking Systems Using Neural Networks

Chin-Cheng Chang and Iuon-Chang Lin

Chapter 15. A Perceptually Tuned Watermarking Scheme for Digital Images Using Support Vector Machines

Chin-Cheng Chang and Iuon-Chang Lin 
Chapter 16. Recent Development of Visual Cryptography 459 Kuo-Feng Hwang and Chin-Cheng Chang

Chapter 17. Watermark Embedding System Based on Visual Cryptography 481

Feng-Hsing Wang, Lakhmi C. Jain, and Jeng-Shyang Pan

Chapter 18. Spread Spectrum Video Data Hiding, Interleaving and Synchronization Yun Q. Shi, Jiwu Huang, and Heung-Kyu Lee

\section{Part IV. Practical Issues in Watermarking and Copyright Protection}

Chapter 19. Video Watermarking: Approaches, Applications, and Perspectives Alessandro Piva, Roberto Caldelli, and Mauro Barni

Chapter 20. Quantization Index Modulation Techniques: Theoretical Perspectives and A Recent Practical Application Brian Chen

Chapter 21. Digital Watermarking for Digital Rights Management Sai Ho Kwok

Chapter 22. Watermark for Industrial Application Zheng Liu and Akira Inoue

Appendix

Appendix A. VQ-Based Scheme I

Appendix B. VQ-Based Scheme II 
Appendix C. Spatial-Based Scheme

Appendix D. GATraining Program for Spatial-Based Scheme

Appendix E. Visual Cryptography

Appendix F. Modified Visual Cryptography

Appendix G. VC-Based Scheme

Appendix H. Gain/Shape VQ-Based Watermarking System

Authors' Contact Information 